\title{
Longer-term outcomes after bicuspid aortic valve repair in 142 patients
}

\author{
Mojyan Safari MD ${ }^{1}$ | Nadejda Monsefi MD ${ }^{2}$ | Afsaneh Karimian-Tabrizi ${ }^{1}$ | \\ Alexandra Miskovic MD ${ }^{1}$ | Arnaud Van Linden $M^{1}$ | Pavel Zacek MD, PhD $^{3}$ | \\ Anton Moritz MD $^{1}$ | Thomas Walther MD ${ }^{1}$ | Tomas Holubec MD, PhD ${ }^{1}$ (])
}

\author{
${ }^{1}$ Department of Cardiovascular Surgery, \\ University Hospital Frankfurt and Johann \\ Wolfgang Goethe University Frankfurt, \\ Frankfurt, Germany \\ ${ }^{2}$ Department of Cardiac Surgery, University \\ Hospital Bonn, Bonn, Germany \\ ${ }^{3}$ Department of Cardiac Surgery, Faculty of \\ Medicine in Hradec Kralove, University \\ Hospital Hradec Kralove and Charles \\ University, Hradec Kralove, Czech Republic

\section{Correspondence} \\ Tomas Holubec, Theodor-Stern-Kai 7, 60596 \\ Frankfurt/Main, Germany. \\ Email: tomasholubec@email.cz

\section{Funding information} \\ The study was supported by the Grant Agency \\ of Charles University Progress Q40/4.
}

\begin{abstract}
Background: The aim of this study was to evaluate the longer-term results of bicuspid aortic valve (BAV) repair with or without aortic root replacement.

Methods: From 1999 to 2017, 142 patients with or without aortic root dilatation who underwent repair of a regurgitant BAV were included in the study. Ninetyfour patients underwent isolated BAV repair (Group 1; median age 43 years) and 48 patients underwent valve-sparing aortic root replacement plus BAV repair (aortic valve reimplantation-Group 2; median age 48 years). Median clinical follow-up time was 5.9 years (range 0.5-15) in Group 1 and 3 years (range 0.5-16) in Group 2, respectively.

Results: In-hospital mortality was $1 \%$ in Group 1 , and $2 \%$ in Group $2(p=.6)$. The 5 - and 10 -year survival was $93 \pm 2.9 \%$ and $81 \pm 5.8 \%$ in Group 1 and $96 \pm 3.1 \%$ and $96 \pm 3.1 \%$ in Group 2, respectively $(p=.31)$. Eleven patients of Group $1(1.7 \%$ / patient-year) and five patients of Group 2 (2.2\%/patient-year) underwent reoperation of the aortic valve $(p=.5)$. The 5 - and 10-year freedom from reoperation were $93.0 \pm 2.1 \%$ and $77.1 \pm 7.1 \%$ in Group 1 and $93.0 \pm 5.0 \%$ and $76.7 \pm 9.6 \%$ in Group $2(p=.83$ ), respectively. At the latest follow-up, only two patients of Group 1 and 1 patient of Group 2 had AV regurgitation $=2^{\circ}(p=.7)$. The cumulative linearized incidence of all valve-related complications (bleeding, stroke, endocarditis, and reoperation) was 2.9\%/patient-year in Group $1 \%$ and $4 \%$ patient-year in Group 2, respectively $(p=.6)$.

Conclusions: Isolated BAV repair and combined aortic valve reimplantation plus BAV repair provide good clinical longer-term outcomes with relatively low reoperation rate and durable valve function.
\end{abstract}

KEYWORDS

aortic root replacement, aortic valve repair, aortic valve-sparing 


\section{1 | INTRODUCTION}

Bicuspid aortic valve (BAV) morphology is a well-known cardiac anomaly with an incidence of about $1 \%-2 \%$ in the adult population. ${ }^{1}$ In comparison with tricuspid morphology BAV is more frequently associated with pathologies such as valve incompetence due to leaflet dysfunction, dilatation of the aortic annulus, aortic root, and/or ascending aorta, its prevalence varies between $20 \%$ and $80 \% .^{2-4}$ Repair of the BAV is technically challenging because of the complex pathology like changes in aortic root geometry with or without primary cusp pathology. There are durable surgical strategies for the treatment of BAV related aortic regurgitation or aortic root dilatation that have been developed over the past 25 years and moreover accepted and used successfully by other groups. ${ }^{5-9}$

The aim of this study was to analyze the longer-term results of BAV repair with and without aortic root replacement.

\section{2 | MATERIALS AND METHODS}

\section{1 | Study population}

From January 1999 to December 2017, 142 consecutive patients underwent repair of a regurgitant BAV with or without root or ascending aorta enlargement at our hospital. Patients with isolated BAV repair ( $n=94$; Group 1 ) and patients with valve-sparing aortic root replacement plus BAV repair (aortic valve reimplantation - David procedure; $n=48$; Group 2) were included in this analysis.

Before surgery, all patients were routinely examined by transthoracic echocardiography (TTE), coronary angiography, and/or cardiac computed tomography (CT). Intraoperative transesophageal echocardiography (TEE) was performed in all patients to evaluate valve function pre- and postcardiopulmonary bypass to facilitate the surgical procedure and to assess the immediate result of AV surgery as well as the left ventricular function during weaning from cardio-pulmonary bypass and adequacy of de-airing of cardiac chambers. The echocardiographic classification of residual/recurrent AV regurgitation was as follows: Grade 0-none/trace; Grade 1trivial; Grade 2-mild; Grade 3-moderate; and Grade 4-severe. Every patient received a TTE at discharge.

All patients were followed up prospectively and systematically by means of annually mailed questionnaires or phone interviews and/or by clinical assessment and TTE in our outpatient clinic. For patients not seen personally we retrieved clinical assessment and echocardiography reports from the attending cardiologist.

The median age of Group 1 was 43 years (range 18-70; 14\% female) and 48 years (range $24-71 ; 10 \%$ female) in Group 2, respectively ( $p=.05$ ). Most of the patients had aortic regurgitation (AR) $\geq 2^{\circ}$ (83\% in Group 1 and $73 \%$ in Group 2; $p=.2$ ). The $17 \%$ of Group 1 patients had $A R=1^{\circ}$ and aneurysm of the ascending aorta. In Group 2 the aortic root and ascending aorta was enlarged with mean diameter of $4.5 \pm 0.7 \mathrm{~cm}$ and $5.0 \pm 0.9 \mathrm{~cm}$ ), respectively. Significantly more patients in Group $1 \mathrm{had}$ severe AR preoperatively than patients in Group 2 ( $73 \%$ vs. $52 \%, p=.01$ ). The patient's preoperative characteristics are summarized in Table 1.

Clinical and echocardiographic follow-up was complete in $98 \%$ for both groups. Median clinical follow-up time was 5.9 years (range $0.5-15$ ) in Group 1 and 3 years (range 0.5-16) in Group 2, respectively. The median echocardiographic follow-up time was 5.9 years (range $0.5-15$ ) in Group 1 and 3 years (0.5-16) in Group 2, respectively.

This study was approved was by the Institutional Review Board (Reference number: 422/12) and informed consent was obtained from each patient.

\section{2 | Surgical techniques}

The aim of BAV repair was to reconstitute the valve's normal geometry and function. Valve repair was performed only in patients with delicate leaflets without calcification or postendocarditic defects. Therefore, accurate preoperative echocardiography with a precise

\begin{tabular}{lllll} 
& All & Group 1 & Group 2 & $p$ value \\
\hline Number & 142 & 94 & 48 & \\
\hline Age (median, range; years) & $47(18-71)$ & $43(18-70)$ & $48(24-71)$ & .05 \\
\hline Male & $124(87 \%)$ & $81(86 \%)$ & $43(90 \%)$ & .6 \\
\hline Hypertension & $82(58 \%)$ & $50(53 \%)$ & $32(67 \%)$ & .2 \\
\hline Diameter of ascending aorta (cm) & $4.5 \pm 0.9$ & $4 \pm 0.8$ & $5 \pm 0.9$ & $<.01$ \\
\hline Renal insufficiency & $22(15 \%)$ & $13(14 \%)$ & $9(19 \%)$ & .4 \\
\hline Diabetes mellitus & $4(3 \%)$ & $3(3 \%)$ & $1(2 \%)$ & .6 \\
\hline Previous cardiac surgery & $5(4 \%)$ & $4(4 \%)$ & $1(2 \%)$ & .5 \\
\hline Chronic obstructive pulmonary disease & $13(9 \%)$ & $8(9 \%)$ & $5(10 \%)$ & .5 \\
\hline Emergent operation & $2(1 \%)$ & $1(1 \%)$ & $1(2 \%)$ & .6 \\
\hline NYHA class (mean) & $2 \pm 0.8$ & $2 \pm 0.8$ & $2 \pm 0.7$ & .2 \\
\hline
\end{tabular}

TABLE 1 Patient characteristics

Note: Group 1: bicuspid AV repair; Group 2: bicuspid AV reimplantation.

Abbreviations: AV, Aortic valve; NYHA, New York Heart Association classification. 
evaluation of cusp quality and intraoperative inspection of the aortic cusps were essential. The ascending aorta and right atrium were cannulated for cardio-pulmonary bypass (CPB), respectively bicaval venous cannulation was applied in concomitant mitral or tricuspid valve procedures. The right axillary artery was cannulated for CPB in patients who underwent additional aortic arch replacement. The aorta was cross-clamped, a transverse aortotomy was performed and cold blood cardioplegia was administered selective through the coronary ostia.

\section{3 | Cusp plication, pericardial patch augmentation}

The standard surgical repair technique we applied in patients with BAV has been described previously. ${ }^{521,22}$ The asymmetry of the bicuspid aortic root often results in a higher coaptation level of the nonfused leaflet. We observed a higher localization of the annular attachment of the fused leaflet in the outflow tract. To compensate for the mismatch in the coaptation level and surface of BAV the fused leaflet was corrected correspondingly by plication and/or pericardial patch augmentation (Figure 1).

In detail, the free margin of the cusp was plicated by using a central plication with a 5-0 suture (Cardiony $l^{\circledR}$, Peters Surgical, France) until the free margin reached the height of the nonprolapsing reference cusp. Additional pericardial patch augmentation was applied to augment the fused leaflet and overcorrect the coaptation height to increase the coaptation surface and restore the valve's normal geometry. We used an autologous pericardial patch that was treated with $0.9 \%$ glutaraldehyde solution for $10 \mathrm{~min}$ before application. The patch was then sutured to the free edge of the fused leaflet with a running suture using a 5-0

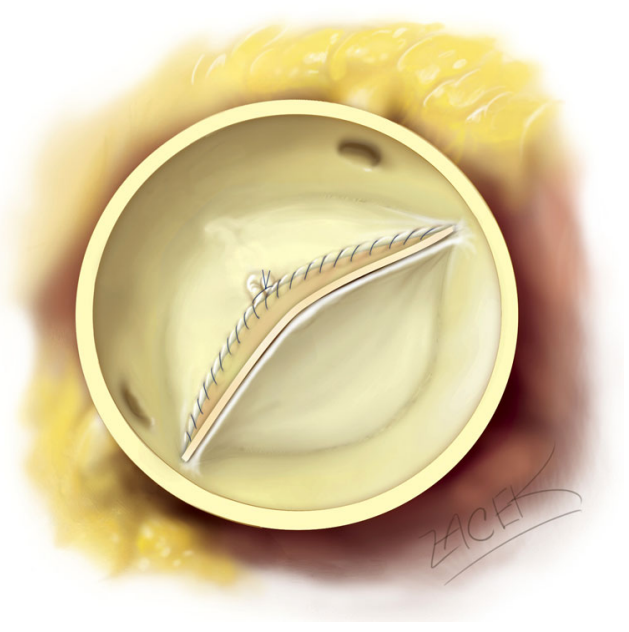

FIGURE 1 Illustration showing a combination of central plication and pericardial patch augmentation in bicuspid aortic valve repair. After central plication of the free edge, an autologous pericardial patch is sutured to the free edge of the fused cusp with a running suture suture (Cardionyl ${ }^{\circledR}$, Peters Surgical, France). Afterward, the patch was cut to a height of about $2 \mathrm{~mm}$ above the corresponding cusp.

Concomitant reduction aortoplasty, ascending aorta, or aortic arch replacement were performed in patients with aortopathy or aneurysm.

\subsection{Dilatation of the aortic root}

In patients with aortic root dilatation, the aortic valve reimplantation (David procedure) was performed. ${ }^{10}$ Briefly, a Dacron straight graft (Hemashield, Maquet, Germany) was used for the David procedure. The Dacron graft was sized according to the formula (leaflet height in $m m \times 1.5)+2 m m$. Over the years, we modified the David procedure: we placed three stitches at the annular base of the Dacron graft creating pseudoneosinuses and later we added three additional stitches at the level of the commissures to create a neosinus to obtain a more physiological shape. ${ }^{11}$

The repaired BAV was assessed by intraoperative transesophageal echocardiography. Anticoagulation was not required postoperatively except in case of atrial fibrillation or history of pulmonary embolism.

\section{5 | Statistical analysis}

Statistical analyses were calculated with the Biometrical Analysis of Sampling (BIAS 11.06 Software, Germany). Continuous and discrete variables are reported as mean \pm standard deviation $(S D)$ or median and range for data not normally distributed. Categorical and ordinal variables are presented using the number and percentage of observations. Continuous and discrete variables were compared using a two-sample $t$-test or Mann-Whitney test, where appropriate. Categorical and ordinal variables were compared using a Pearson's $\chi^{2}$ test or Fischer's exact test, where appropriate. The probability of freedom from an event was calculated according to the Kaplan-Meier method. Freedom-from-event curves were compared by log-rank test. A $p$ value of less than .05 was defined as statistically significant.

\section{3 | RESULTS}

\section{1 | Surgical procedures}

Minimally invasive approach via partial upper sternotomy was performed in the majority of patients (61\% in Group 1 and 67\% in Group $2 ; p<.01)$. The remaining patients were operated via complete sternotomy. The perioperative results and surgical procedures are summarized in Table 2.

Isolated ascending aorta replacement for the treatment of aortic aneurysm was performed in four patients (4\%) of Group 1 and 38 patients (79\%) of Group 2 ( $p<.01$; Table 2). In Group 2 additional hemiarch replacement was performed in nine patients (19\%) and one patient received complete aortic arch replacement using elephant 
TABLE 2 Perioperative results and surgical procedures

\begin{tabular}{|c|c|c|c|}
\hline & Group 1 & Group 2 & $p$ value \\
\hline \multicolumn{4}{|l|}{ Surgical procedures (n) } \\
\hline $\begin{array}{l}\text { Isolated ascending aorta } \\
\text { replacement }\end{array}$ & $4(4 \%)$ & $38(79 \%)$ & $<.01$ \\
\hline $\begin{array}{l}\text { Ascending aorta and } \\
\text { hemiarch or arch } \\
\text { replacement }\end{array}$ & 0 & $9(19 \%)$ & $<.01$ \\
\hline Elephant trunk & 0 & $1(2 \%)$ & .3 \\
\hline Reduction aortoplasty & $19(20 \%)$ & 0 & $<.01$ \\
\hline Complete sternotomy & 37 (39\%) & $16(33 \%)$ & $<.01$ \\
\hline Partial upper sternotomy & $57(61 \%)$ & 32 (67\%) & $<.01$ \\
\hline $\begin{array}{l}\text { Leaflet plication of the } \\
\text { aortic valve }\end{array}$ & $80(85 \%)$ & 42 (88\%) & .8 \\
\hline $\begin{array}{l}\text { Pericardial patch } \\
\text { augmentation }\end{array}$ & $84(89 \%)$ & 34 (71\%) & $<.01$ \\
\hline \multicolumn{4}{|l|}{$\begin{array}{l}\text { Concomitant } \\
\text { procedures (n) }\end{array}$} \\
\hline $\begin{array}{l}\text { Coronary artery bypass } \\
\text { grafting }\end{array}$ & $2(2 \%)$ & $4(8 \%)$ & .1 \\
\hline Mitral valve repair & $8(9 \%)$ & $1(2 \%)$ & .2 \\
\hline Tricuspid valve repair & $4(4 \%)$ & 0 & .2 \\
\hline \multicolumn{4}{|l|}{ Perioperative data } \\
\hline $\begin{array}{l}\mathrm{CPB} \text { time (median, } \\
\text { range; } \text { min) }\end{array}$ & $\begin{array}{l}125 \\
(86-251)\end{array}$ & $\begin{array}{l}181 \\
\quad(124-247)\end{array}$ & $<.01$ \\
\hline $\begin{array}{l}\text { Cross-clamp time } \\
\quad \text { (median, range; min) }\end{array}$ & $\begin{array}{l}88 \text { (range } \\
58-169)\end{array}$ & $\begin{array}{r}136 \text { (range } \\
83-194)\end{array}$ & $<.01$ \\
\hline $\begin{array}{l}\text { Intensive care unit stay } \\
\quad \text { (median, range; days) }\end{array}$ & $1(1-13)$ & $1(1-7)$ & .2 \\
\hline Need for re-exploration & $6(6 \%)$ & $7(15 \%)$ & .1 \\
\hline $\begin{array}{l}\text { Neurological event } \\
\text { (stroke) }\end{array}$ & 0 & 0 & \\
\hline In-hospital mortality & $1(1 \%)$ & $1(2 \%)$ & .6 \\
\hline
\end{tabular}

Note: Group 1: bicuspid AV repair; Group 2: bicuspid AV reimplantation. Abbreviations: $\mathrm{AV}$, aortic valve; $\mathrm{CPB}$, cardio-pulmonary bypass.

trunk technique due to a greater extent of the aortic arch aneurysm. Reduction aortoplasty was performed in 19 patients (20\%) of Group 1. Significantly more patients of Group 1 received pericardial patch augmentation $(n=84)$ in comparison with Group 2 patients $(n=34$; $p<.01)$. The rate of leaflet plication was similar in both groups (80 patients of Group 1 and 42 patients of Group 2; $p=.8$ ).

\subsection{Concomitant procedures}

There was no significant difference in the rate of concomitant procedures between both groups. Additionally, eight patients of Group 1 and one patient of Group 2 underwent mitral valve repair $(p=.2)$.
Coronary artery bypass grafting was performed in two patients of Group 1 and four patients of Group $2(p=.1)$. Four patients of Group 1 underwent tricuspid valve repair (Table 2).

\section{3 | Early postoperative outcomes}

There was no operative death. In-hospital mortality was $1 \%(n=1)$ in Group 1 and $2 \%(n=1)$ in Group $2(p=.6)$. Cause of death was multiorgan failure ( $n=1$, Group 1) and low cardiac output syndrome ( $n=1$, Group 2). There was no significant difference between the two groups regarding intensive care unit stay (mean of $1.1 \pm 2$ days in Group 1 vs. mean of $1.6 \pm 1.5$ days in Group 2; $p=.2$ ). Cardio-pulmonary bypass time was significantly longer in Group 2 (median of $125 \mathrm{~min}$, range 86-251 in Group 1 vs. $181 \mathrm{~min}$, range 124-247 in Group 2; $p<.01$ ). Similar results were observed for the cross-clamp time (Table 2). Re-exploration for bleeding was necessary in six patients of Group 1 and in seven patients of Group 2, respectively $(p=.1)$. No neurological events were observed in both groups.

\section{4 | Postoperative echocardiography data before discharge from hospital}

Echocardiographic results before discharge revealed 98\% $(n=92)$ of Group 1 had AR $\leq 1^{\circ}(80 \%$ had no AR) and $98 \%(n=47)$ of Group 2 had $A R \leq 1^{\circ}(94 \%$ had no $A R)(p=.7)$. Only one patient of Group 1 had $A R=2^{\circ}$. Aortic regurgitation more than $2^{\circ}$ was not observed at the time of discharge. There was no significant difference between the two groups regarding left ventricular ejection fraction (LVEF) at time of discharge $(53 \pm 10 \%$ mean in Group 1 vs. $55 \pm 9 \%$ mean in Group 2; $p=.3$ ). The mean aortic valve gradients (Pmean) were similar in both groups (11 $\pm 6 \mathrm{mmHg}$ in Group 1 vs. $9 \pm 4 \mathrm{mmHg}$ in Group 2; $p=.1$ ).

\subsection{Follow-up results}

In the follow-up period time we observed 10 late deaths in Group 1 and one in Group 2, respectively $(p=.07)$. Cause of death was cardiac-related in four patients of Group 1 and one patient in Group 2, respectively. The estimated 5 - and 10-year survival was $93 \pm 2.9 \%$ and $81 \pm 5.8 \%$ in Group 1 and $96 \pm 3.1 \%$ and $96 \pm 3.1 \%$ in Group 2, respectively and did not differ between the groups significantly ( $p=.31$; Figure 2$)$.

During the follow-up 16 patients required reoperation of the $\mathrm{AV}$, 11 patients of Group 1 (1.7\%/patient-year) and five patients of Group $2(2.2 \% /$ patient-year) $(p=.5)$. The estimated 5 - and 10 -year freedom from reoperation was $93.0 \pm 2.1 \%$ and $77.1 \pm 7.1 \%$ in Group 1 and $93.0 \pm 5.0 \%$ and $76.7 \pm 9.6 \%$ in Group 2 , respectively and did not differ significantly between the two groups ( $p=.83$; Figure 3 ). We analyzed the cause of the reoperation in detail. In Group 1 the cause of reoperation was severe AR due to infective endocarditis in four patients. Four other patients underwent reoperation due to severe recurrent $A R$ as a consequence of leaflet perforation $(n=1)$, leaflet 


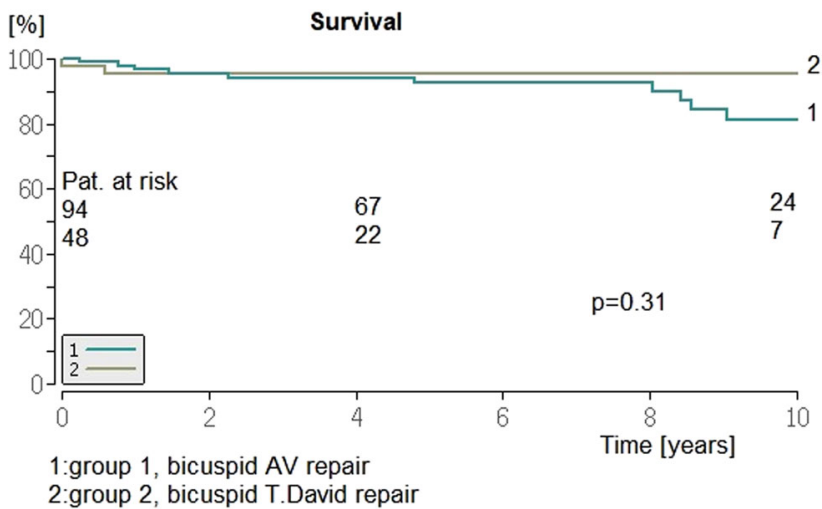

FIGURE 2 Kaplan-Meier curve showing survival after bicuspid aortic valve repair versus aortic valve reimplantation

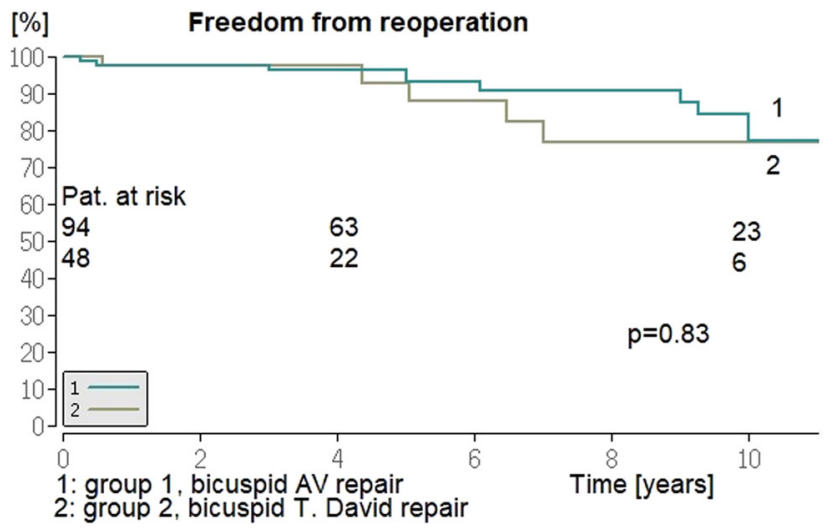

FIGURE 3 Kaplan-Meier curve showing freedom from reoperation after bicuspid aortic valve repair versus aortic valve reimplantation

prolapse $(n=1)$, detachment of the pericardial patch at the commissure $(n=1)$, or root dilatation $(n=1)$. A re-repair was possible only in the patient with the detachment of the pericardial patch. Root replacement (biological valved-conduit) was performed in one patient. The remaining six patients received aortic valve replacement. Aortic valve stenosis due to calcification of both leaflets was the cause of reoperation in three other patients and they underwent $\mathrm{AV}$ replacement. In Group 2 three patients underwent reoperation due to infective endocarditis. Two other patients were reoperated due to severe recurrent $A R$. In one of them, the regurgitation was caused by a leaflet prolapse. In the other case, AR was due to calcification of the fused leaflet. In both cases the pericardial patch was intact. The AV was replaced with a prosthesis in all five patients.

During the follow-up period, four patients of Group 1 and 3 patients of Group 2 developed AV endocarditis $(p=.6)$. There was no significant difference in the late stroke rate as the linearized incidence was $0.2 \%$ / patient-year in Group 1 vs. $0.4 \% /$ patient-year Group $2(p=.6)$. The rate of bleeding events was not significantly different between the two groups $(p=.4)$. One patient of Group 1 developed gastric bleeding, another one (also Group 1) had cerebral bleeding with minor stroke. One of them was on anticoagulation (coumadin) because of atrial fibrillation.
TABLE 3 Follow-up data

\begin{tabular}{|c|c|c|c|}
\hline & Group 1 & Group 2 & $p$ value \\
\hline Late mortality; n (\%/pt-yr) & $10(1.6)$ & $1(0.4)$ & .07 \\
\hline Endocarditis; $n$ (\%/pt-yr) & 0 & $3(1.3)$ & .6 \\
\hline Stroke & $1(0.2)$ & $1(0.4)$ & .6 \\
\hline All cases of bleeding; $n$ (\%/pt-yr) & $2(0.3)$ & 0 & .4 \\
\hline Anticoagulation related bleeding & $1(0.2)$ & 0 & .7 \\
\hline Reoperation; $n$ (\%/pt-yr) & $11(1.7)$ & $5(2.2)$ & .5 \\
\hline Reoperation or $\mathrm{AR} \geq 2^{\circ} ; n$ (\%/pt-yr) & $13(2.1)$ & $6(2.7)$ & .53 \\
\hline Valve related complications; $n$ (\%/pt-yr) & $18(2.9)$ & $9(4)$ & 6 \\
\hline
\end{tabular}

Note: Group 1: bicuspid AV repair; Group 2: bicuspid AV reimplantation. Abbreviations: AR, aortic regurgitation; AV, aortic valve; pt-yr, patient-year.

The cumulative linearized incidence of all valve-related complications (bleeding, stroke, endocarditis, and reoperation) was $2.9 \% /$ patient-year in Group 1 and 4\%/patient-year in Group 2, respectively $(p=.6)$. The cumulative linearized incidence of all valve-related complications (bleeding, stroke, endocarditis, and reoperation) was 2.9\%/patient-year in Group 1\% and $4 \%$ patient-year in Group 2, respectively $(p=.6)$. The follow-up results are presented in Table 3.

At the latest follow-up, 70 patients (97\%) of Group 1 and 40 patients (98\%) of Group 2 had $\mathrm{AR}<2^{\circ}(p=.7)$. Only two patients of Group 1 and 1 patient of Group 2 had $A R=2^{\circ}$, respectively $(p=.7)$. We did not observe any patients with recurrent $A R>2^{\circ}$. The $A V$ Pmean gradient was significantly higher in Group $1(17 \pm 12 \mathrm{mmHg})$ in comparison to Group $2(9 \pm 5 \mathrm{mmHg})(p<.01$; Table 4).

The cumulative linearized incidence of reoperation or recurrent $A R \geq 2^{\circ}$ was $2.1 \%$ /patient-year in Group 1 and 2.7\%/patient-year in Group 2, respectively $(p=.53)$. The estimated 5 - and 10 -year freedom from reoperation or $\mathrm{AR} \geq 2^{\circ}$ was $93.0 \pm 3.1 \%$ and $75.1 \pm 7.2 \%$ in Group 1 and $93.0 \pm 5.1 \%$ and $76.6 \pm 9.6 \%$ in Group 2, respectively and did not differ significantly between the two groups ( $p=.73$; Figure 4).

There was an association between reoperation or recurrent $A R \geq$ $2^{\circ}$ and pericardial patch augmentation. Ninety-two percent of patients in Group 1 and 67\% patients in Group 2 who had to be reoperated on the $A V$ or had recurrent $A R \geq 2^{\circ}$ in the follow-up period received pericardial patch augmentation at time of primary operation.

At the latest follow-up, the mean New York Heart Association (NYHA) class was $1.4 \pm 0.6$ in Group 1 and $1.4 \pm 0.5$ in Group 2, respectively $(p=.5)$.

\section{4 | DISCUSSION}

Patients with BAV present with multiple configurations of the cusps, commissures, sinuses with/without additional aortopathy. ${ }^{12}$ The mechanism of AR in BAV can be diverse. Cusp prolapse, fenestration, or a restrictive cusp can cause AR. In addition, annulus dilatation or root enlargement can be existent. Therefore, during BAV repair, the surgeon has 
TABLE 4 Echocardiographic data

\begin{tabular}{|c|c|c|c|}
\hline Preoperative & $\begin{array}{l}\text { Group } \\
1(n=94)\end{array}$ & $\begin{array}{l}\text { Group } \\
2(n=48)\end{array}$ & $p$ value \\
\hline$A R=1^{\circ}$ & $16(17 \%)$ & $13(27 \%)$ & .2 \\
\hline$A R=2^{\circ}$ & $9(10 \%)$ & $10(21 \%)$ & .06 \\
\hline$A R=3^{\circ}$ & 69 (73\%) & 25 (52\%) & .01 \\
\hline Ejection fraction (\%) & $57 \pm 7$ & $58 \pm 12$ & .7 \\
\hline LVEDD (cm) & $6 \pm 1$ & $6 \pm 1$ & .2 \\
\hline Pmax AV (mmHg) & $17 \pm 8$ & $14 \pm 8$ & .1 \\
\hline Pmean AV (mmHg) & $10 \pm 5$ & $8 \pm 5$ & .1 \\
\hline $\begin{array}{l}\text { Postoperative (before } \\
\text { discharge from hospital) }\end{array}$ & $\begin{array}{l}\text { Group } \\
\qquad 1(n=93)\end{array}$ & $\begin{array}{l}\text { Group } \\
\qquad 2(n=47)\end{array}$ & $p$ value \\
\hline$A R<2^{\circ}$ & 92 (99\%) & 47 (100\%) & .7 \\
\hline$A R=2^{\circ}$ & $1(1 \%)$ & 0 & .7 \\
\hline Ejection fraction (\%) & $53 \pm 10$ & $55 \pm 9$ & .3 \\
\hline LVEDD (cm) & $6 \pm 1$ & $5 \pm 1$ & .2 \\
\hline Pmax AV (mmHg) & $17 \pm 8$ & $15 \pm 5$ & .1 \\
\hline Pmean AV (mmHg) & $11 \pm 6$ & $9 \pm 4$ & .1 \\
\hline Latest follow-up & $\begin{array}{l}\text { Group } \\
\qquad 1(n=72)\end{array}$ & $\begin{array}{l}\text { Group } \\
\qquad 2(n=41)\end{array}$ & $p$ value \\
\hline$A R<2^{\circ}$ & 70 (97\%) & 40 (98\%) & .7 \\
\hline$A R=2^{\circ}$ & $2(3 \%)$ & $1(2 \%)$ & .7 \\
\hline Ejection fraction (\%) & $58 \pm 9$ & $59 \pm 7$ & .4 \\
\hline LVEDD (cm) & $5 \pm 1$ & $5 \pm 1$ & .5 \\
\hline$P_{\max } A V(m m H g)$ & $26 \pm 18$ & $15 \pm 9$ & $<.01$ \\
\hline$P_{\text {mean }} \mathrm{AV}(\mathrm{mmHg})$ & $17 \pm 12$ & $9 \pm 5$ & $<.01$ \\
\hline
\end{tabular}

Note: Group 1: bicuspid AV repair; Group 2: bicuspid AV reimplantation. $A R \geq 3^{\circ}$ was not observed.

Abbreviations: AR, aortic regurgitation; AV, aortic valve; LVEDD, left ventricular end-diastolic diameter $(\mathrm{cm}) ; \mathrm{P}_{\max } \mathrm{AV}$, maximal pressure across the aortic valve $(\mathrm{mmHg}) ; \mathrm{P}_{\text {mean }} \mathrm{AV}$, mean pressure across the aortic valve $(\mathrm{mmHg})$.

to consider all aspects of pathological changes in cusp and aortic root to restore the valve geometry. ${ }^{7}$ Aortic valve repair is a feasible alternative to valve replacement that is referred to as Class IC indication in the 2017 European Association for Cardio-Thoracic Surgeons/European Society of Cardiology Guidelines for management of valvular heart disease. ${ }^{13} \mathrm{Re}-$ construction of BAV has been already described in the 1990s by Cosgrove et al. with triangular resection and plication of the prolapsing cusp. ${ }^{14}$ We used that technique and modified it in our series to create a larger coaptation surface. The pericardial patch augmentation was evolved in addition to the mid-leaflet plication technique. ${ }^{5}$ In patients with BAV and additional root dilatation we combined BAV repair with aortic valve reimplantation procedure (David procedure) to create a competent valve and restore the root geometry. We performed a subgroup analysis and compared the results of isolated BAV repair (Group 1) with the David procedure in patients with BAV. In our series, the

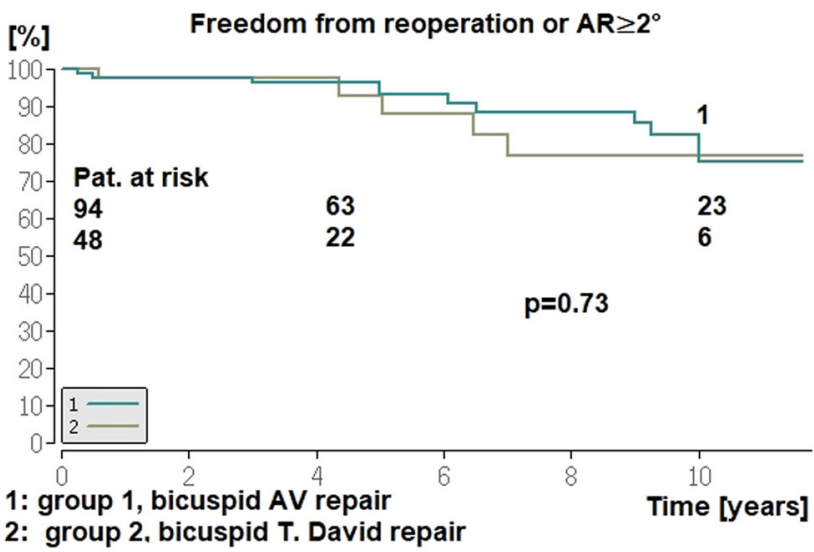

FIGURE 4 Kaplan-Meier curve showing freedom from reoperation or recurrent aortic valve regurgitation $\geq 2^{\circ}$ after bicuspid aortic valve repair versus aortic valve reimplantation

in-hospital mortality was $1 \%(n=1)$ in Group 1 , and $2 \%(n=1)$ in Group 2 $(p=.6)$. We did not observe any neurological events (stroke) perioperatively. The BAV repair data of our study demonstrate that it is a safe procedure and comparable to published in-hospital mortality rates between $0 \%$ and $1 \% .6,8,15$ Cardio-pulmonary bypass duration was significantly longer in Group 2 (median $125 \mathrm{~min}$ in Group 1 vs. $181 \mathrm{~min}$ in Group 2; $p$.01). Similar results were observed for cross-clamp time. This might be related to the additional root reimplantation technique in Group 2 that is a complex procedure. The fact that significantly more patients of Group 1 received pericardial patch augmentation (89\%) in comparison of Group 2 patients $(71 \%, p<.01)$ did not have an impact on the reoperation rate when comparing the two groups. The 5 - and 10 -year freedom from reoperation were similar in both groups, $(p=.83)$. Reported 10-year freedom from reoperation ranges between $78 \%$ and $81 \%$ in large series with BAV repair which is comparable with our results., ${ }^{9,15,16}$ In our series, we observed a high number of endocarditis $(n=7)$ at the late follow-up which was the cause of reoperation in $44 \%$ of patients. It is hard to explain why the observed endocarditis rate is so high. The AV Pmean was significantly higher in group $1(17 \pm 12 \mathrm{mmHg})$ in comparison to Group 2 $(9 \pm 5 \mathrm{mmHg}, p<.01$; Table 4). This might be related to a slightly higher AV Pmean of group 1 patients preoperatively that increased in course of time.

Pericardial patch augmentation in our cohort seems to have a negative impact on AV repair durability as $92 \%$ of patients of Group 1 who had to be reoperated on the $A V$ or had recurrent $A R \geq 2^{\circ}$ in the follow-up period received pericardial patch augmentation at time of primary operation. Similar trend was observed in Group 2 (67\%). This finding is in line with several studies, which have consistently shown that the use of pericardial patch as partial cusp replacement or augmentation was an independent risk factor for early and longer-term failure. ${ }^{16-18}$ The reason for the negative impact could be explained by the higher stress that might be generated due to pericardial patch on the fused leaflet which can lead to faster degeneration of the leaflet. Al Halees et al. ${ }^{19}$ described a similar thesis in 2005. A pericardial patch could also be a risk factor for infective endocarditis. In this context we resigned from this technique of BAV repair and do not apply it anymore. 
Our 5- and 10-year survival were good in both groups and did not differ significantly ( $p=.31$; Figure 2$)$. Other published data with reported 10 -year survival between $92 \%$ and $100 \%$ are comparable with our results. ${ }^{6,15,16}$ The inferior 10-year survival in Group 1 in comparison with Group 2 might be related to a longer follow-up period of Group 1 and could also be influenced by more concomitant procedures at time of operation that have been performed in Group 1 (mitral and tricuspid valve procedures; Table 2). The cumulative linearized incidence of all valve-related complications (bleeding, stroke, and endocarditis, reoperation) was $2.9 \%$ /patient-year in Group 1, respectively $4 \% /$ patient-year in Group 2, $(p=.6)$ which is lower than the reported incidence of prosthetic valve complications of $5 \%$ per patient per year. ${ }^{20}$ Our results demonstrate that BAV repair techniques are safe and feasible. The longer-term durability of BAV repair is encouraging.

\subsection{Study limitations}

We have to point out that the comparison between bicuspid aortic valve repair and bicuspid David repair was initially performed for subgroup analysis within BAV repair techniques. However, due to different aortic valve/root pathology, these two groups are not appropriately comparable. Therefore, we put emphasis on bicuspid repair techniques as a whole, and for better illustration of the results the two subgroups were described.

\section{5 | CONCLUSION}

In summary, aortic valve repair in BAV pathology, with or without additional root repair (David procedure) provides good longer-term outcomes with relatively low mortality and an acceptable reoperation rate. We can conclude both technics are suitable for the treatment of bicuspid aortic valve disease.

\section{ACKNOWLEDGMENT}

The study was supported by the Grant Agency of Charles University Progress Q40/4. Open access funding enabled and organized by Projekt DEAL.

\section{CONFLICT OF INTERESTS}

The authors declare that there are no conflict of interests.

\section{ORCID}

Tomas Holubec (D) http://orcid.org/0000-0003-2366-0880

\section{REFERENCES}

1. Bravemann AC, Guven H, Beardslee MA, Makan M, Kates AM, Moon MR. The bicuspid aortic valve. Curr Probl Cardiol. 2005;30: 470-522.

2. Della Corte A, Bancone C, Quarto C, et al. Predictors of ascending aortic dilatation with bicuspid aortic valve: a wide spectrum of disease expression. Eur J Cardiothorac Surg. 2007; 31:397-404.
3. Siu SC, Silversides CK. Bicuspid aortic valve disease. J Am Coll Cardiol. 2010;55:2789-2800.

4. Fedak PW, Verma S, David TE, Leask RL, Weisel RD, Butany J. Clinical and pathophysiological implications of a bicuspid aortic valve. Circulation. 2002;106:99-4.

5. Doss M, Moidl R, Wood JP, Miskovic A, Martens S, Moritz A. Pericardial patch augmentation for reconstruction of incompetent bicuspid aortic valves. Ann Thorac Surg. 2005;80:304-307.

6. Ehrlich T, de Kerchove L, Vojacek J, et al. State-of-the art bicuspid aortic valve repair in 2020. Progn Cardiovasc Dis. 2020;63:457-464.

7. Ouzounian M, Feindel CM, Manlhiot C, David C, David TE. Valvesparing root replacement in patients with bicuspid versus tricuspid aortic valves. J Thorac Cardiovasc Surg. 2019;158:1-9.

8. Holubec $T$, Zacek $P$, Jamaliramin $M$, et al. Valve cuspidity: a risk factor for aortic valve repair? J Card Surg. 2014;29:585-592.

9. Mangini $A$, Contino $M$, Romagnoni $C$, et al. Aortic valve repair: a ten-year single-centre experience. Interact Cardiovasc Thorac Surg. 2014;19:28-35.

10. David TE, Feindel CM. An aortic valve-sparing operation for patients with aortic incompetence and aneurysm of the ascending aorta. J Thorac Cardiovasc Surg. 1992;103:617-621.

11. Moritz A, Risteski P, Dogan S, et al. Six stitches to create a neosinus in David-type aortic rot resuspension. J Thorac Cardiovasc Surg. 2007;133:560-562.

12. Sievers HH, Schmidtke C. A classification system for the bicuspid aortic valve from 304 surgical specimens. J Thorac Cardiovasc Surg. 2007;133:1226-1233.

13. Baumgartner H, Falk V, Bax JJ, et al. ESC/EACTS Guidelines for the management of valvular heart disease. Eur Heart J. 2017;38: 2739-2791.

14. Casselman FP, Gillinov AM, Akhrass R, Kasirajan V, Blackstone EH, Cosgrove DM. Intermediate-term durability of bicuspid aortic valve repair for prolapsing leaflet. Eur J Cardiothorac Surg. 1999;15:302-308.

15. Svensson LG, Al Kindi AH, Vivacqua A, et al. Long-term durability of bicuspid aortic valve repair. Ann Thorac Surg. 2014;97:1539-1547.

16. Aicher D, Kunihara T, Abou Issa O, Brittner B, Graber S, Schäfers HJ. Valve configuration determines long-term after repair of the bicuspid aortic valve. Circulation. 2011;123:178-185.

17. Karliova I, Schneider U, Ehrlich T, Schäfers HJ. Results of pericardial patches in tricuspid and bicuspid aortic cusp repair. Ann Thorac Surg. 2020;109:728-735.

18. Mosala Nezhad Z, de Kerchove L, Hechadi J, et al. Aortic valve repair with patch in non-rheumatic disease: indication, techniques and durability. Eur J Cardiothorac Surg. 2014;46:997-1005.

19. Al Halees Z, Al Shahid M, Al Sanei A, Sallehuddin A, Duran C. Up to 16 years follow-up of aortic valve reconstruction with pericardium: a stentless readily available cheap valve? Eur J Cardiothorac Surg. 2005;28: 200-205.

20. Jamieson WR, Burr LH, Miyagishima RT, et al. Carpentier-Edwards supra-annular aortic porcine bioprosthesis: clinical performance over 20 years. J Thorac Cardiovasc Surg. 2005;130:994-1000.

21. Thudt M, Papadopoulos N, Monsefi N, et al. Long-term results following pericardial patch augmentation for incompetent bicuspid aortic valves: a single center experience. Ann Thorac Surg. 2017; 103:1186-1192.

22. Salem R, Zierer A, Karimian-Tabrizi A, et al. Aortic valve repair for aortic insufficiency or dilatation: Technical evolution and long-term outcomes. Ann Thorac Surg. 2020;110:1967-1974.

How to cite this article: Safari M, Monsefi N, Karimian-Tabrizi

$A$, et al. Longer-term outcomes after bicuspid aortic valve repair in 142 patients. J Card Surg. 2021;36:4645-4651. https://doi.org/10.1111/jocs.16006 